\title{
A Existência Prévia de Doenças do Aparelho Circulatório Acelera a Mortalidade por COVID-19?
}

\author{
Does Existence of Prior Circulatory System Diseases Accelerate Mortality Due to COVID-19?
}

\author{
Carlos Dornels Freire de Souza, ${ }^{10}$ Thiago Cavalcanti Leal, ${ }^{1}$ Lucas Gomes Santos ${ }^{1}$ \\ Universidade Federal de Alagoas - Campus Arapiraca, ${ }^{1}$ Arapiraca, AL - Brasil
}

\section{Caro Editor,}

Os primeiros casos de doença de coronavírus 2019 (COVID-19) foram identificados na metrópole de Wuhan, capital da província de Hubei, na República Popular da China. ${ }^{1}$ Nela, observou-se um surto de pneumonia de rápida progressão e de origem indeterminada associada à exposição comum ao mercado de frutos do mar da cidade. ${ }^{1}$ Em 31 de dezembro de 2019, a China notificou o surto à Organização Mundial da Saúde (OMS). ${ }^{1}$ Um mês depois, em 30 de Janeiro, a OMS declarou situação de emergência internacional e, em 11 de março, foi declarada pandemia pela doença. ${ }^{2}$

No Brasil, o primeiro caso foi confirmado em 26 de fevereiro de 2020, em São Paulo. Em 17 de março, foi registrada a primeira morte no país e, três dias depois (20 de março), o Ministério da Saúde reconheceu a transmissão comunitária em todo território nacional. Em 15 de maio, o Brasil ocupava a sexta posição mundial em casos acumulados, com mais de 200.000 infectados e mais de 13.000 mortes. $^{3}$

Dentre os aspectos mais relevantes a serem observados no curso da pandemia são os grupos de maior risco, dos quais se destacam os indivíduos com a idade superior a 60 anos e aqueles com comorbidades cardiovasculares como fatores de pior prognóstico e maior letalidade quando infectados pelo novo coronavírus. ${ }^{4}$

Este estudo objetivou analisar a associação entre a existência prévia de doenças do aparelho circulatório e o tempo (em dias) entre o início dos primeiros sintomas e a data do óbito por COVID-19.

Trata-se de um estudo de caso-controle envolvendo dados de 374 óbitos por COVID-19 registrados no estado de Pernambuco. Os dados foram obtidos da página eletrônica de monitoramento da COVID-19 do estado (https://dados.seplag. pe.gov.br/apps/corona.html), em 07 de maio de 2020. Após a coleta, o banco de dados passou por ajustes das variáveis, que consistiu na avaliação dos sinais/sintomas e comorbidades.

\section{Palavras-chave}

Coronavirus; COVID-19; Pandemia; Síndrome Respiratória Aguda Grave/complicações; Comorbidades; Fatores de Risco; Diabetes; Hipertensão; Dispnea.

\section{Correspondência: Carlos Dornels Freire de Souza •}

Universidade Federal de Alagoas - Campus Arapiraca - Medicina -

Av. Manoel Severino Barbosa, S/N. CEP 57309-005, Arapiraca, AL - Brasil

E-mail: carlos.freire@arapiraca.ufal.br

Artigo recebido em 17/05/2020, revisado em 21/05/2020,

aceito em 21/05/2020
Após a adequação, 197 indivíduos possuíam doença do aparelho circulatório prévia, dos quais 187 apresentavam data do início dos sintomas e data do óbito. Esses indivíduos compuseram o grupo de casos. Para a composição do grupo controle, foram selecionados 187 óbitos que não possuíam comorbidades relatadas. A seleção desses óbitos foi aleatória, obedecendo a data de início dos primeiros sintomas.

No estudo, foram consideradas as seguintes variáveis: comorbidades existentes (nenhuma, uma, duas e três ou mais) e o tempo (em dias) entre a data dos primeiros sintomas e o óbito por COVID-19. Para a análise estatística, foi utilizado o teste de Kolmogorov-Smirnov para a avaliação inicial da normalidade dos dados. Uma vez constatada a violação do pressuposto de distribuição gaussiana, a associação entre as variáveis foi avaliada pelo teste não paramétrico $\bigcup$ de MannWhitney. As análises consideraram significância de 5\% e foram realizadas com o auxílio do software SPSS versão 24.0 (IBM Corporation). Por utilizar dados de domínio público, nos quais não é possível a identificação dos indivíduos, este estudo dispensou a aprovação pelo Comitê de Ética em Pesquisa.

A média e desvio-padrão (média \pm DP) e mediana e intervalo interquartil (mediana - IIQ) de dias entre o início dos primeiros sintomas e a data do óbito de toda a população do estudo $(\mathrm{n}=374)$ foram 11,52 $( \pm 7,75)$ e 10 (IIQ 10), respectivamente. Do grupo casos, 38 (20,3\%) possuíam apenas uma doença do aparelho circulatório; 79 (42,2\%) possuíam duas comorbidades/fatores de risco e 70 (37,5\%) possuíam três ou mais comorbidades/fatores de risco. Salientase que pelo menos uma das comorbidades estava relacionada com o sistema circulatório (Figura 1).

Observou-se diferença significativa entre o número de dias entre o início dos primeiros sintomas e o óbito ao comparar os dois grupos. Os valores observados no grupo controle (média $\pm \mathrm{DP}=13,32 \pm 7,2$; mediana $-\mathrm{IIQ}=11$ -11) foram superiores ao grupo que possuía comorbidades relatadas (média $\pm \mathrm{DP}=9,73 \pm 7,8$; mediana $-\mathrm{IIQ}=$ 7 - 9) (Figura 1).

O presente estudo aponta para uma progressão mais rápida da COVID-19 em quem possui comorbidades cardiovasculares, com uma média de dias do início dos primeiros sintomas ao óbito inferior em quase quatro dias (3,9 dias na média e 4,0 na mediana), quando comparados o grupo que possuía enfermidades cardiovasculares prévias e o grupo controle. Este processo decorre dos efeitos do SARS-CoV-2 no organismo humano, como a ligação do vírus à enzima conversora de angiotensina 2 (ECA2) encontrada nas superfícies das células cardíacas, renais e pulmonares. ${ }^{4}$

DOI: https://doi.org/10.36660/abc.20200486 


\section{a) Comparação entre grupo (Grupo controle X Grupo de casos)}

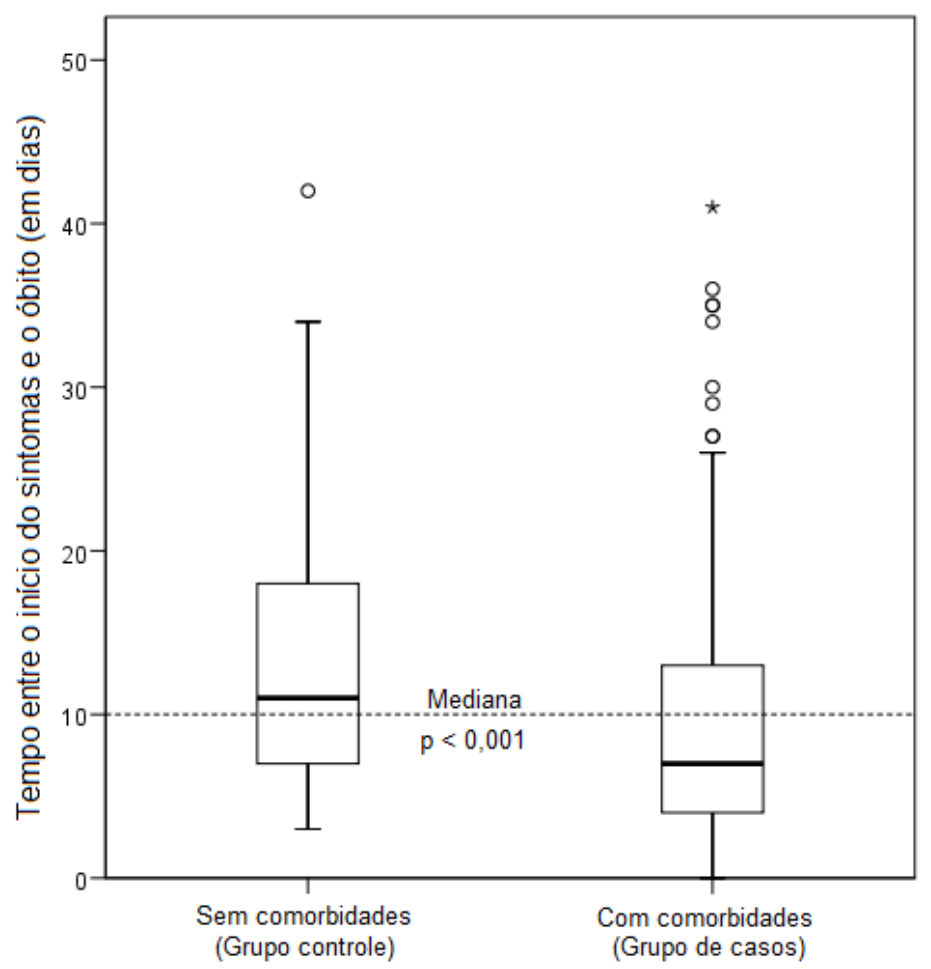

Figura 1 - Comparação entre o número de dias entre o início dos primeiros sintomas e o óbito por COVID-19, segundo presença/ausência de comorbidades. Brasil, 2020.

A exposição das glicoproteínas relacionadas ao novo coronavírus à ECA2 promove a sua internalização junto com o vírus, o que diminui a densidade de ECA2 na membrana ${ }^{5,6}$ e consequentemente o efeito cardioprotetor relacionado à hipertrofia cardíaca, à fibrose miocárdica e à inflamação. Nesse sentido, associa-se a redução de ECA2 à exacerbação das cardiopatias existentes, tais como insuficiência cardíaca e hipertensão arterial, contribuindo com a mais rápida progressão e o agravamento do quadro clínico respiratório e cardiovascular dos indivíduos com COVID-19.

Com base nos resultados observados, a presença de comorbidades cardiovasculares acelera a mortalidade por COVID-19. Ademias, outros estudos ainda devem ser realizados a fim de mensurar o impacto de cada doença cardiovascular no risco de mortalidade.

\section{Referências}

1. Xinhuanet. The Chinese Center for Disease Control detects a large number of new coronaviruses in the seafood market in southern China in Wuhan [Internet]. [place unknown]: Zhao Yanxin. 2020 Jan 27 [Cited 2020 May 15]. Available from: http://www.xinhuanet.com/2020-01/27/c_1125504355.htm

2. World Health Organization. (WHO). Strengthening health security by implementing the International Health Regulations (2005) [Internet]. [place unknown]; 2020 [Cited 2020 Apr 15]. Available from: http://www.who.int/ ihr/procedures/pheic/en/

3. Brasil. Ministério da Saúde. Coronavirus Brasil. Painel de casos de doença pelo coronavírus 2019 (COVID-19) [Internet]. [Acessado em 2020 May 15]. Disponível em:: https://covid.saude.gov.br/.

4. Abassi Z, Assady S, Khoury EE, Heyman SN. Angiotensin-converting enzyme 2: an ally or a Trojan horse? Implications to SARS-CoV-2-related

cardiovascular complications. Am J Physiol Heart Circ Physiol. [Internet]. 2020 Mar 27 [Cited 2020 May 15];318:H1080-H1083. DOI 10.1152/ ajpheart.00215.2020. Available from: https://journals.physiology.org/doi/ pdf/10.1152/ajpheart.00215.2020

5. Hamming I, Cooper ME, Haagmans BL, Hooper NM, Korstanje R, Osterhaus ADME, et al. The emerging role of ACE2 in physiology and disease. J Pathol. [Internet]. 2007 Jan 25 [Cited 2020 May 15];212:1-11. DOI 10.1002/ path.2162. Available from: https://www.ncbi.nlm.nih.gov/pmc/articles/ PMC7167724/\#

6. Zheng YY, Ma YT, Zhang JY, Xie X. COVID-19 and the cardiovascular system. Nature Rev Cardio [Internet]. 2020 Mar 05 [Cited 2020 May 15];17:259-60. DOI 10.1038/s41569-020-0360-5. Available from: https://www.nature. com/articles/s41569-020-0360-5 